\title{
ACTITUD Y ACADEMIA EN TIEMPOS DE PANDEMIA
}

\section{Juan Carlos Arango Arango \\ Institución Educativa San José (Itagüí, Antioquía, Colombia) \\ microhem.arangoarango@gmail.com}

\section{RESUMEN}

El objetivo principal del estudio fue analizar la posibilidad de ir más allá del trabajo por competencias hacia el desarrollo del pensamiento configuracional y crítico enmarcado en el modelo sociocrítico, en medio de la contingencia sanitaria provocada por la pandemia de la COVID-19. Para ello se basó en un caso específico donde se relaciona el rendimiento académico y las actitudes de 139 estudiantes del grado octavo de la Institución Educativa San José del municipio de Itagüí, del departamento de Antioquia (Colombia). Los resultados obtenidos indican la necesidad de una pedagogía, que aún en medio de las crisis, procuren incentivar en los jóvenes una aprendizaje más significativo y transformador.

Palabras clave: pensamiento configuracional, pensamiento crítico

\section{ATTITUDE AND ACADEMY IN TIMES OF PANDEMIC} ABSTRACT

The main objective of the study was to analyze the possibility of going beyond competency based work towards the development of configurational and critical thinking framed in the sociocritical model, in the midst of the health contingency caused by the COVID-19 pandemic. For this, it was based on a specific case where the academic performance and attitudes of 139 eighth grade students from the San José Educational Institution in the municipality of Itagüí, department of Antioquia (Colombia) are related. The results obtained indicate the need for a pedagogy, which, even in the midst of crises, tries to encourage more meaningful and transformative learning in young people.

Key words: configurational thinking, critical thinking 


\section{INTRODUCCIÓN}

Atraer e incentivar a los jóvenes hacia la construcción de conocimiento útil y transformador, alejándolos de la apatía y la aversión, se convierte hoy en día no solo en una necesidad, sino en todo un imperativo del sistema educativo, que aporte en la elaboración de propuestas cívicas, políticas, económicas, educativas, etc, pero este debe realizarse de forma propositiva, creativa, racional, crítica, que conlleve hacia una verdadera intervención con pensamiento social que produzca los cambios requeridos para poder convivir en sociedad (De Alba, García y Santiesteban, 2012).

El desarrollo del pensamiento configuracional desde el modelo sociocrítico de la educación, permite educar para la intervención y el cambio social, la justicia, la convivencia democrática, además de la promoción y el ejercicio de los derechos humanos, porque es aquí que en la perspectiva crítica de las diferentes problemáticas se pueden producir soluciones innovadoras y participativas, permitiendo que la labor docente se centre en una relación educador y educando de forma humanizada (Castro, 2013).

Bajo el modelo sociocrítico buscando el desarrollo del pensamiento configuracional, las aulas de clase sufren procesos de transformación pasando de aspectos tradicionales a verdaderos espacios de acción y reflexión que posibilitan la lúdica y la participación activa de los estudiantes mediante la acción comunicativa, además de fomentar la autonomía y la toma de decisiones con conciencia crítica (Sánchez y Viveros, 2019), es decir, un diálogo permanente con el otro, con constantes procesos de revisión, análisis e identificación de métodos para el enfoque científico de las instituciones educativas (Castro, 2013).

Entonces se pueden construir espacios donde el estudiante comprenda la importancia de la educación como forma de alcanzar equilibrio social, ampliar las posibilidades para las personas, mejorar las vías de acceso a oportunidades de salud, empleo, ingresos y seguridad, en sí, como sostiene Flórez (citado en Rodríguez, 2014), la educación como proceso transformador y propulsor de cambios, con perspectiva humanista y colaborativa.

Formar sujetos, ciudadanos responsables de sí mismos, de sus semejantes, del medio ambiente, es decir, ser competentes para convivir, esa es unas de las grandes responsabilidades de la educación y se necesita que la labor docente en las instituciones educativa ofrezca ambientes y espacios que permitan la deliberación y la construcción de significados y simbolismos, además de docentes que asuman el papel de ser verdaderos intelectuales transformadores de la pedagogía, que propicien la vinculación entre las instituciones educativas y la comunidad. 
Pero sucede que debido a la contingencia por la COVID-19, los estudiantes de todo el país no han podido regresar a las aulas desde el mes de marzo de 2020, por lo que, desde el Ministerio de Educación Nacional, se han trazado directrices para realizar la labor docente educativa desde los hogares, aprovechando para esto las redes sociales y diferentes plataformas. Ha sido todo un proceso maratónico de acomodamiento y adaptación tanto para docentes como estudiantes y padres de familia, ante los nuevos retos planteados.

Surge entonces la necesidad de continuar con la formación de estudiantes, por lo que se debe potenciar el proceso mediante la reflexión, acción y teorización y la utilización de problemáticas del entorno próximo para buscarles solución con la ayuda de estrategias colectivas que suponen un gran esfuerzo por relacionar las áreas de los diferentes docentes y llevarlos a un estado de verdaderos investigadores pedagógicos, que permitan que el estudiante pase de la operacionalización hacia un estado que comprenda lo que hace, ser sujetos y ciudadanos, construyendo así verdaderos espacios de encuentro que incrementan el sentido de pertenencia con el entorno propio (Sánchez y Viveros, 2019).

Para lograr esto, el proceso formativo desde los hogares, debe trascender del trabajo por habilidades y competencias del modelo basado por competencias hacia uno que procure en los estudiantes el desarrollo del pensamiento configuracional enmarcado en el modelo sociocrítico de la educación, que contribuya a la preparación de los jóvenes a que comprendan lo que hacen y fomente en ellos la participación democrática y la toma de decisiones en su propio entorno.

Para hacer este tránsito es fundamental trabajar con base en la problematización y la investigación, mediante la construcción de condiciones organizativas, motivando así la pregunta, la curiosidad, el asombro, el riesgo, la indagación, la significación, el respeto por las particularidades de profesores, estudiantes y de las mismas dinámicas institucionales (Sánchez y Viveros, 2019), mediante la interpretación autorreflexiva, la deliberación, los actos discursivos y las dos herramientas pisopedagógicas y didácticas con mayor poder configurador, como son la metacognición y la metafectividad (Ortiz, 2014).

\section{MODELO EDUCATIVO SOCIOCRÍTICO}

El modelo educativo sociocrítico permite un currículo, una pedagogía y una didáctica que fomentan el avance en los niveles de comprensión y ofrecen prácticas creadoras, innovadoras, pertinentes, significativas, dialógicas y colaborativas, que influyen en el mejoramiento de la calidad del servicio (Mora, 2014) y que valoran a los sujetos, que comparten valores y costumbres, que producen identidad compartida, respetando la intrasubjetividad y la significación construida en 
conjunto, para solucionar problemáticas que los aquejan, reconociendo así a la propia realidad como praxis con autorreflexión y consenso (Unzueta, 2011).

Este modelo posee doce componentes como son, el Estado Educador, que propone, ejecuta y legisla leyes y demás normas jurídicas; las condiciones socioculturales y económicas, que relaciona los contextos y los actores; los recursos, los cuales incluyen los físicos y humanos e influyen en los resultados de los procesos educativos; el clima escolar, que incluye los ambiente dentro y fuera de las aulas, como también, la comunicación entre los actores; la familia, como organismo fundamental de socialización y enculturación, en sus diferentes niveles de clasificación; los docentes y el equipo directivo, en sus diferentes representaciones, posiciones sociopolíticas y formación disciplinaria; los estudiantes, como eje central del proceso educativo, respetando la heterogeneidad de estos; la comunidad, donde se va a dar el verdadero proceso de transformación; el desarrollo del proceso de aprendizaje y enseñanza, que busca alcanzar mayores grados de pensamiento y comprensión, para mejorar los niveles de calidad; la evaluación, para medir el funcionamiento del sistema educativo y sus subsistemas; los alcances, no mirándolos solo como resultados finales sino durante el proceso de aprendizaje y enseñanza y pueden ser tangibles y cognoscitivos; y el desarrollo de potencialidades y condiciones socioculturales, personales y antropológicas de los actores (experiencias y saberes previos), reconociendo así que la práctica pedagógica, no se debe suponer que parte desde cero, lo cual rescata los procesos de socialización e interacción vividos y que se llevan a las instituciones educativas, lo cual es de carácter significativo (Mora, 2014).

Sus métodos permiten superar el individualismo y proponen pensar reflexivamente en intereses comunes para avanzar del positivismo determinista hacia enfoques que ofrecen toda una gama de posibilidades e interpretaciones de forma holística, teniendo en cuenta lo técnico o relaciones entre personas y naturaleza, social o relaciones entre sujetos por medio de la cultura y las normas y emancipatorio para construir identidad en medio de la diversidad, como lo sostiene Habermas, en sus intereses de conocimiento con finalidades prácticas (Unzueta, 2011).

Al centrarse en la construcción social del conocimiento y teniendo en cuenta las teorías contextuales y culturales, el aprendizaje es un proceso de transformación interna (Ortiz, 2014), donde se premian los aportes de las vivencias construidas desde lo colectivo, favoreciendo así acciones de metacognición como la creación, lo cual se manifiesta en la concentración, la comprensión, los significados, el intercambio de experiencias, la reflexión, etc, apropiándose de los aprendizajes significativos, la intersubjetividad, la cooperación, la colaboración, el lenguaje y la comunicación, con su papel de intermediación entre el pensamiento y su expresión, además de la construcción de pensamiento colectivo y de la memoria cultural (Unzueta, 2011). 
La pedagogía crítica es teoría y práctica reflexiva y propositiva con comprensión y acción sobre la realidad que favorece la interculturalidad, la cual surge como medio alternativo que posibilita la transformación de las formas de enseñanza excluyentes y autoritarias hacia una más incluyente que exige la necesidad de la comunicación (Gómez, y Gómez, 2011). La pedagogía considerada como reflexión acerca de la educación y valorada por la comunidad académica se debe entender no como un campo sino como una configuración conceptual comprensiva (Ortiz, 2017) y Zambrano (citado en Ortiz, 2017) la considera como el espacio donde se visibilizan los componentes traídos a la realidad.

\section{PENSAMIENTO CONFIGURACIONAL}

El modelo pedagógico o pedagogía configuracional, fundamentado en la teoría del aprendizaje neuroconfigurador centra el proceso de enseñanza y aprendizaje y sus componentes en el funcionamiento del cerebro humano y busca entender como aprenden los estudiantes y como deben enseñar los docentes (Ortiz, 2014) y al momento de desarrollar el pensamiento crítico, no solo se necesita poseer habilidades sino también disposición, motivación, iniciativa, discernimiento y apertura al cambio (Minte e Ibagón, 2017).

Llinás citado en (Ortiz, 2014), el aprendizaje "es un medio para facilitar que la función del sistema nervioso se adapte a los requisitos de la naturaleza, del mundo en que vivimos. Aunque a primera vista los detalles del mundo externo parecen pertenecer al dominio ontogenético, probablemente son las características filogenéticamente prefijadas del organismo las que permiten darle el significado al detalle, al ámbito de lo que está sucediendo ahora".

El aprendizaje neuroconfigurador se considera como un proceso neuropsicosocial, de configuración, creación y/o modificación de redes y circuitos neuronales, que transforma al estudiante y adapta sus experiencias en los diferentes contextos, gracias a su ejercicio comunicativo, con causas filogenéticas y no ontogenéticas, por lo que el cerebro se remodela y se rediseña en respuesta al entorno, fomentando así el desarrollo de la creatividad, la interpretación y la comprensión, teniendo siempre presente, que estas modificaciones cerebrales, no tienen su fundamento en la anatomía ni en los genes, sino que son una consecuencia de la experiencia y el contexto, que modifica redes, lo cual moviliza recuerdos e informaciones, además de dominar destrezas, por lo que las neuronas se activan y las sinápsis se hacen más fuertes, además de crear nuevas neuronas y nuevas sinapsis, es decir, neuroplasticidad (Ortiz, 2014)

El pensamiento configuracional asocia e integra aportes desde el enfoque constructivista (Álvarez y Fuentes), constituye una aproximación epistemológica, teórica y metodológica que 
interpreta los procesos sociales como procesos de desarrollo humano que como realidad objetiva construyen en los sujetos, significados y sentidos (Álvarez, Fuentes y Matos, 2004). Es un proceso en el que se relacionan acciones neuronales del cerebro y mentales del sujeto, es un proceso afectivo-cognitivo complejo y holístico, que expresa la capacidad que tiene el ser humano de aplicar sus conocimientos en un contexto diverso, problémico y cambiante, utilizando de manera sistémica, armónica y coherente sus habilidades y destrezas, así como sus valores y actitudes para solucionar problemas y situaciones del contexto que le permitan adaptarse y transformar el entorno para construir un entorno de vida digna (Ortiz, 2011).

El pensamiento configuracional es consciente y se fortalece del pensamiento subconsciente y del inconsciente y en él se presenta la tríada del pasado vivido, la identidad preconfigurada y el futuro configurado anticipadamente, las cuales se estructuran de forma sistémica y dialéctica de forma dinámica y compleja en la mente dotada de subjetividad y las hipótesis se deben desarrollar y argumentar en niveles superiores de comprensión e interpretación (Ortiz, 2011) que configuran relaciones de significación de carácter social entre los sujetos para dar solución a las problemáticas de la misma sociedad (Álvarez et al, 2004).

Todo pensamiento configuracional es sistémico, holístico y complejo, pero no todo pensamiento sistémico, holístico y complejo es configuracional, porque en la teoría de sistemas la abstracción general desde lo concreto no constituye la construcción de modelos, por lo que la sistematicidad necesita ser integrada, además que lo sistémico incluye componentes y estructura, lo configuracional remite a organización, proceso, relaciones, interconexiones, funciones, sentidos, significados y regularidades, es decir, el pensamiento configuracional entonces recurre a la multidiversidad, multidimensionalidad y a la multidisciplinariedad, siempre con la búsqueda de progreso social (Salcedo y Ortiz, 2017).

Como sostiene Morin, el conocimiento es complejo y este posee cuatro principios como son el de la recursividad o refundación donde el ser encuentra que puede redescubrir para refundar y construir nuevas oportunidades, el del ser dialógico o diálogo permanente que permite las relaciones de interculturalidad, unificación en la pluralidad y diversidad y reconocer la diferencia, el ser hologramático que reconoce el todo a partir de las partes y el ser sistémico que reconoce las partes en la organización sistémica. Son estos cuatro fundamentos que permiten que el pensamiento desde la complejidad, permiten mantener el diálogo y la transdisciplinariedad de saberes en unidad (Comboni y Juárez, 2012). 


\section{MÉTODO}

El ejercicio fue realizado en la Institución Educativa San José del Municipio de Itagüí, departamento de Antioquia (Colombia). Esta institución es de carácter público, cuenta con una población de 1630 estudiantes, de sexo femenino, tan solo hay un estudiante de sexo masculino en el grado octavo. La muestra se obtuvo del grado octavo, el cual se encuentra conformado por 5 grupos, para un total de 149 estudiantes, del cual participaron libremente 139, cuyas edades fluctúan entre los 13 y 15 años.

El instrumento quedo conformado por dos cuestionarios. El primero consistió en 5 preguntas que relacionan un tema específico de las ciencias naturales (microorganismos), con las matemáticas básicas y el segundo por 18 preguntas de tipo actitudinal en forma de escala de Likert que van desde el 1 (“Totalmente en desacuerdo"), 2 ("En desacuerdo"), 3 (“Indiferente"), 4 ("De acuerdo") y 5 (Totalmente de acuerdo"), al cual se le aplicó el coeficiente de Cronbach. Estos ítems pretendían observar la actitud de las estudiantes acerca de las clases virtuales durante la pandemia y así relacionarlos con las 5 preguntas de aspecto académico.

\section{PROCEDIMIENTO}

La prueba fue presentada a los estudiantes como parte de un estudio que tenía como objetivo analizar la posibilidad del pensamiento configuracional enmarcado en el modelo sociocrítico, más allá de las competencias y el alejamiento de las aulas de clase tradicionales debido a la pandemia por COVID-19.

Los datos de los dos cuestionarios se recogieron de forma virtual, utilizando formularios de Google y se enviaron los links a los estudiantes por medio de WhatsApp personal y se analizó el cuestionario de conocimientos en relación a los estándares básicos de competencias y los derechos básicos de aprendizaje y el cuestionario actitudinal utilizando el programa SPSS.

\section{RESULTADOS}

El alfa de Cronbach evalúa la confiabilidad del instrumento constituido por medio de escala de Likert, donde los valores comprendidos entre (0.70 y 0.90), indican una buena consistencia interna (Oviedo y Campo-Arias, 2005), el cual fue de (0.706).

\begin{tabular}{|c|c|c|c|}
\hline \multicolumn{3}{|c|}{ Tabla 1 } \\
\hline \multirow{3}{*}{ Casos } & & $\mathbf{N}$ & $\%$ \\
\cline { 2 - 4 } & Válido & 138 & 99.3 \\
\cline { 2 - 4 } & Excluido & 1 & 7 \\
\cline { 2 - 4 } & Total & 139 & 100 \\
\hline
\end{tabular}




\section{ANÁLISIS (CUESTIONARIO UNO)}

\section{Responda las preguntas 1 a 3 de acuerdo con la siguiente información}

Para probar el efecto que tiene una vacuna aplicada a 516 ratones sanos, se realiza un experimento en un laboratorio. El experimento consiste en identificar durante algunas horas la regularidad en el porcentaje de ratones que se enferman al ser expuestos posteriormente al virus que ataca la vacuna. Las siguientes gráficas representan el porcentaje de ratones enfermos al cabo de la primera, segunda y tercera hora de iniciado el experimento.

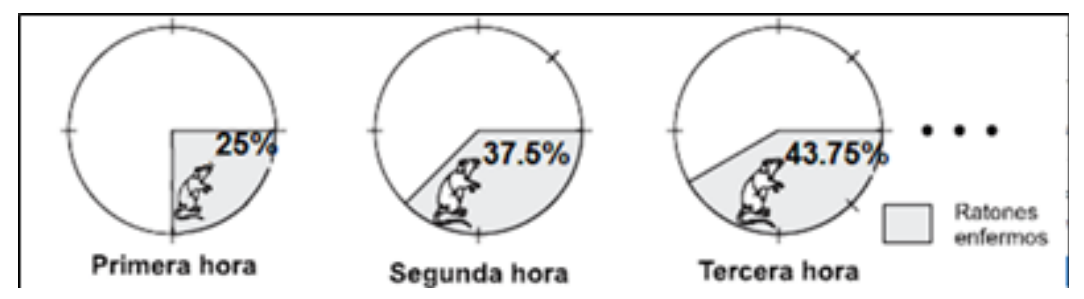

1. Respecto al estado de los ratones con el paso del tiempo NO es correcto afirmar que

a) al cabo de la primera hora hay 129 ratones enfermos.

b) transcurridas dos horas y media hay más ratones sanos que enfermos.

c) al cabo de la primera hora hay 75 ratones sanos.

d) entre la segunda y tercera hora el número de ratones enfermos aumentó en 6,25\%.

(Banco de preguntas de matemática)

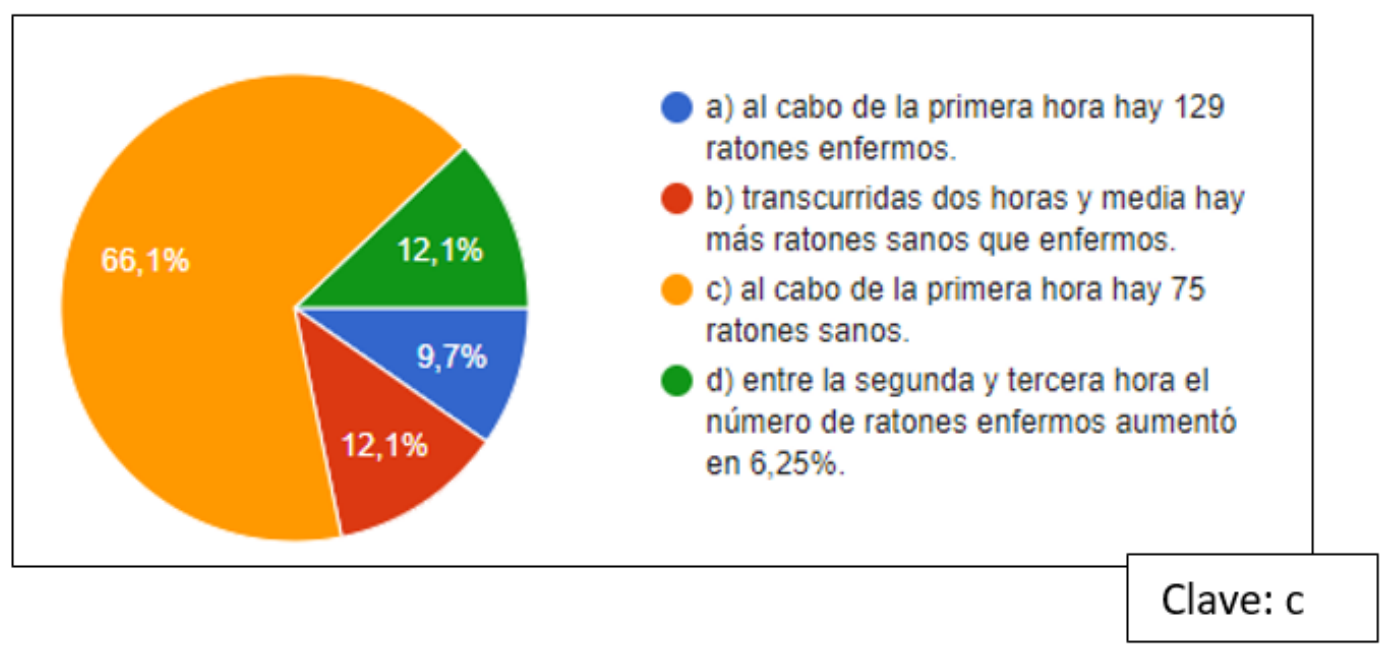

\begin{tabular}{|l|l|}
\hline E.C $8^{\circ}, 9^{\circ}$ & $\begin{array}{l}\text { Utiliza las matemáticas como herramienta para modelar, analizar y presen- } \\
\text { tar datos. }\end{array}$ \\
\hline $\begin{array}{l}\text { DBA } \\
7^{\circ}\end{array}$ & $\begin{array}{l}\text { Comprende y resuelve problemas que involucran los números racionales } \\
\text { con las operaciones (suma, resta, multiplicación, división, potenciación, } \\
\text { radicación) en contextos escolares y extraescolares. }\end{array}$ \\
\hline
\end{tabular}


Se observa cómo el $66,1 \%$ de los estudiantes respondieron correctamente, pero hay un $33.9 \%$ que no. Esta pregunta pertenece a las pruebas Saber 11 y muestra la necesidad de intervenir en cuanto al manejo de operaciones básicas matemáticas, comprensión de problemas, análisis de gráficas, encontrar operaciones ocultas y operacionalizar.

El estudiante debe comprender algunos conceptos que aparecen como: vacuna, virus, regularidad, para ponerlos en contexto y poder entrar a abordar el problema.

Esta situación está muy enfocada al desarrollo de habilidades y competencias, como algo muy conceptual, memorístico, de realizar problemas. Este problema no solo debe enfocarse solo en su solución, sino que debe procurar en el estudiante el pensamiento divergente, que encuentre soluciones de forma creativa.

El problema debe fomentar en el estudiante no solo el aspecto operacional, sino que debe procurar una intencionalidad y significación consciente con proyección social, que encuentre la cotidianidad en estos, sino solo será una ejecución memorística de operaciones sin sentido.

E.C: Estándares básicos de competencias.

DBA: Derechos básicos de competencias.

2. Observando los datos anteriores y considerando la regularidad en el porcentaje de ratones enfermos, un integrante del equipo de investigación representó en la siguiente gráfica el porcentaje de ratones enfermos al cabo de la cuarta hora de iniciado el experimento.

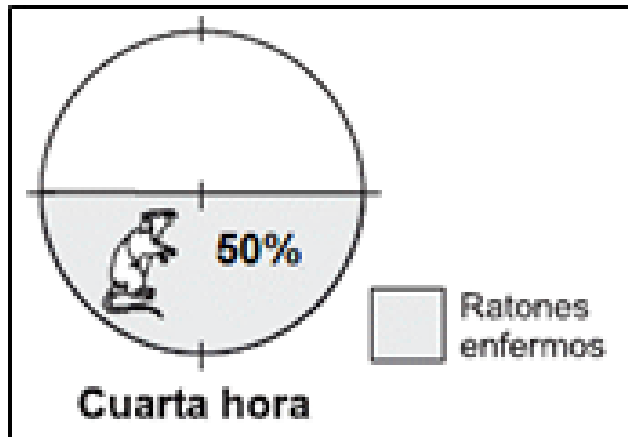

Esta gráfica NO es correcta porque

a) la información que se representa corresponde al porcentaje de ratones enfermos al cabo de la quinta hora de iniciado el experimento.

b) al cabo de la cuarta hora de iniciado el experimento debería haber 3,125\% menos ratones enfermos que los representados.

c) la información que se representa corresponde al porcentaje de ratones enfermos al cabo de tres horas y media de iniciado el experimento.

d) al cabo de la cuarta hora de iniciado el experimento debería haber 56,25\% de ratones enfermos.

(Banco de preguntas de matemática) 


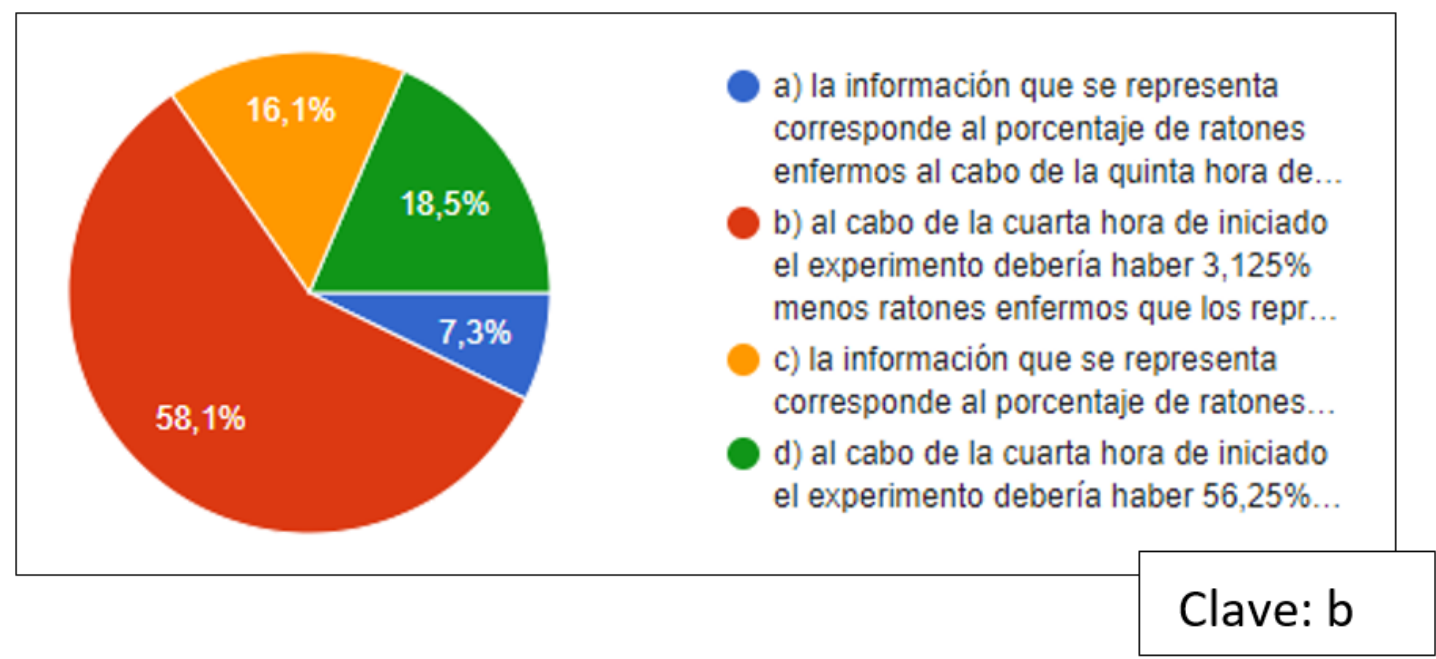

\begin{tabular}{|l|l|}
\hline E.C $8^{\circ}, 9^{\circ}$ & $\begin{array}{l}\text { Identifica y verifica condiciones que influyen en los resultados de un } \\
\text { experimento y que pueden permanecer constantes o cambiar (variables). }\end{array}$ \\
\hline $\begin{array}{l}\text { DBA } \\
7^{\circ}\end{array}$ & $\begin{array}{l}\text { Resuelve problemas en los que se involucran variaciones. } \\
\text { Describe procedimientos para calcular el resultado de una operación (suma, } \\
\text { resta, multiplicación y división) entre números enteros y racionales. }\end{array}$ \\
\hline $\begin{array}{l}\text { Se observa cómo el } 58,1 \% \text { de los estudiantes respondieron correctamente, pero hay un } 41,9 \% \\
\text { que no. Esta pregunta pertenece a las pruebas Saber } 11 \text { y muestra la necesidad de intervenir }\end{array}$ \\
y cuestionar con sentido reflexivo y crítico, para no quedar solo en la superficialidad del acto \\
matemático operacional. \\
$\begin{array}{l}\text { Es necesario no solo fomentar la habilidad y la competencia, sino también disposición, motivación, } \\
\text { iniciativa, disposición e iniciativa al cambio. } \\
\text { En este problema se observa cómo es de necesario prestarles atención a los detalles, para adaptarse } \\
\text { a diferentes contextos, fomentando la creatividad, la comprensión y la interpretación. } \\
\text { Este ejercicio de regularidades y modificaciones muestra la importancia de la experiencia y el } \\
\text { contexto, lo que lleva en sí a demostrar destrezas y habilidades. }\end{array}$ \\
\hline
\end{tabular}

E.C: Estándares básicos de competencias.

DBA: Derechos básicos de competencias

3. La gráfica que representa mejor el porcentaje de ratones enfermos es:

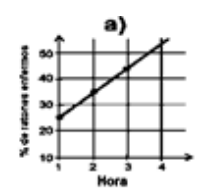

c)

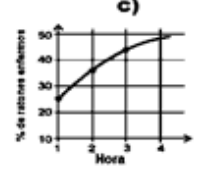

(Banco de preguntas de matemática)

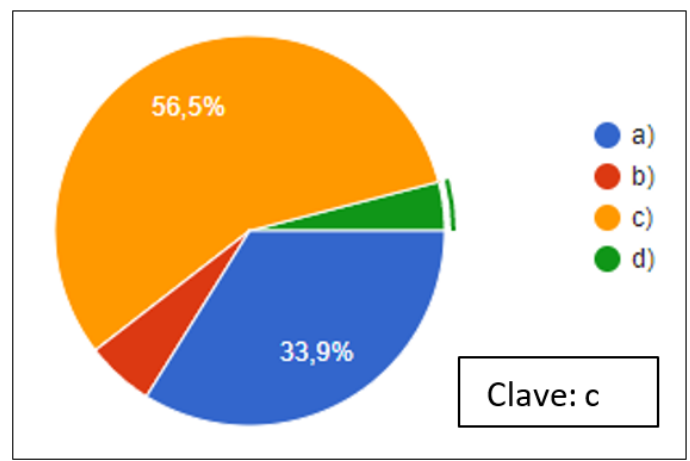




\begin{tabular}{|l|l|}
\hline E.C $8^{\circ}, 9^{\circ}$ & $\begin{array}{l}\text { Analiza la información la información presentada identificando } \\
\text { variaciones, relaciones o tendencias para dar respuesta a las preguntas } \\
\text { planteadas. } \\
\text { Plantea preguntas, diseña y realiza un plan para recolectar la información } \\
\text { pertinente. }\end{array}$ \\
\hline $\begin{array}{l}\text { DBA } \\
7^{\circ}\end{array}$ & $\begin{array}{l}\text { Establece relaciones causales y multicausales entre los datos recopilados. } \\
\text { Persiste en la búsqueda de respuesta a las preguntas. }\end{array}$ \\
\hline $\begin{array}{l}\text { Se observa cómo el 56,5\% de los estudiantes respondieron correctamente, pero hay un 43.5\% que } \\
\text { no. Esta pregunta pertenece a las pruebas Saber 11 y muestra la necesidad de intervenir para que } \\
\text { el estudiante aplique sus conocimientos, habilidades y destrezas en contexto diverso, problémico }\end{array}$ \\
y cambiante para alcanzar mayores niveles de comprensión e interpretación de forma holística y \\
compleja. \\
$\begin{array}{l}\text { El análisis de esta gráfica debe trascender del simple proceso de unir puntos y líneas en ésta, hacia } \\
\text { alcanzar mayores grados de abstracción, de tal manera que el estudiante organice, relacione, } \\
\text { interconecte funciones, encuentre sentidos y significados a las regularidades. } \\
\text { La gráfica muestra el desarrollo de destrezas, puede pasar por alto la oportunidad de llegar a } \\
\text { alcanzar niveles de representación con intencionalidad, es decir, pasar de lo académico a la } \\
\text { autodeterminación y responsabilidad social, construyendo la competencia de aplicar lo que } \\
\text { aprende en su propio entorno. }\end{array}$ \\
\hline
\end{tabular}

E.C: Estándares básicos de competencias.

DBA: Derechos básicos de competencias

\section{Conteste las preguntas 4 y 5 de acuerdo con la siguiente información}

Se desea medir la efectividad de dos medios de cultivo para identificar y contar las bacterias lácticas que prevenían de dos tipos de queso. Para lograr esto, se realizó el experimento que se muestra en los siguientes esquemas:

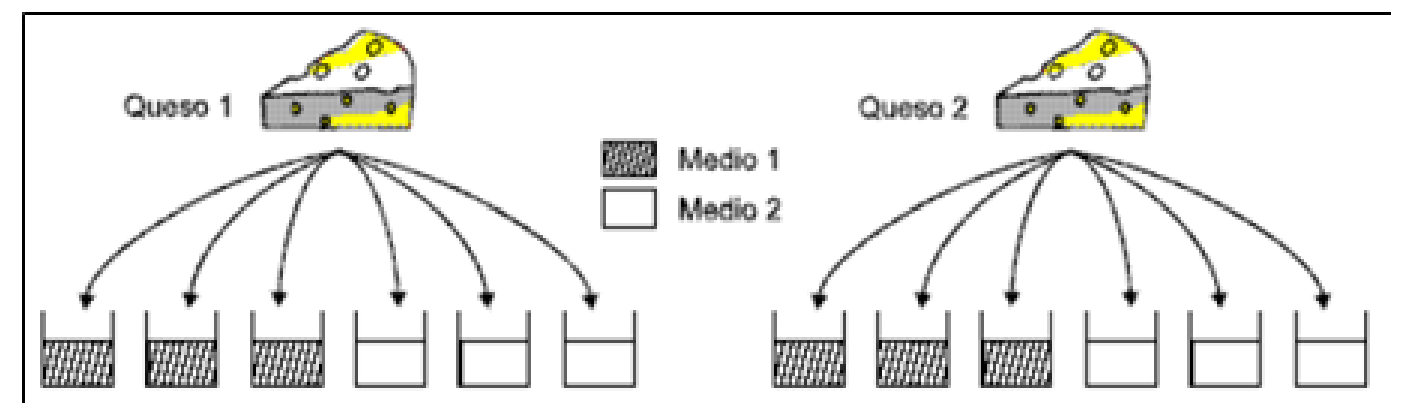


Al cabo de algunos días, se notó que en los medios habían crecido tanto bacterias lácticas como otros tipos de bacterias que contaminaron el medio. Se contó entonces en cada muestra el número de bacterias que creció en cada uno de los medios, obteniendo los siguientes resultados:

\begin{tabular}{|c|c|c|c|c|}
\cline { 2 - 5 } \multicolumn{1}{c|}{} & \multicolumn{2}{c|}{ MEDIO 1 } & \multicolumn{2}{c|}{ MEDIO 2 } \\
\cline { 2 - 5 } \multicolumn{1}{c|}{} & $\begin{array}{c}\text { Bacterias } \\
\text { totales }\end{array}$ & $\begin{array}{c}\% \text { de bacterias } \\
\text { lácticas }\end{array}$ & $\begin{array}{c}\text { Bacterias } \\
\text { totales }\end{array}$ & $\begin{array}{c}\% \text { de bacterias } \\
\text { lácticas }\end{array}$ \\
\hline \multirow{2}{*}{$\begin{array}{c}\text { Bacterias del } \\
\text { Queso 1 }\end{array}$} & 3900 & 66 & 2600 & 100 \\
\cline { 2 - 5 } & 2300 & 60 & 1500 & 90 \\
\hline \multirow{2}{*}{$\begin{array}{c}\text { Bacterias del } \\
\text { Queso 2 }\end{array}$} & 20000 & 93 & 550 & 80 \\
\cline { 2 - 5 } & 3200 & 46 & 560 & 92 \\
\cline { 2 - 5 } & 1200 & 70 & 350 & 100 \\
\hline
\end{tabular}

4. La prueba en la que es más difícil concluir sobre la efectividad del medio de cultivo para el desarrollo de bacterias lácticas debido a la gran variación en los resultados es:

a) el medio 2 para bacterias del queso 1

b) el medio 1 para bacterias del queso 2

c) el medio 2 para bacterias del queso 2

d) el medio 1 para bacterias del queso 1

(Examen de Estado. Banco de preguntas de biología)

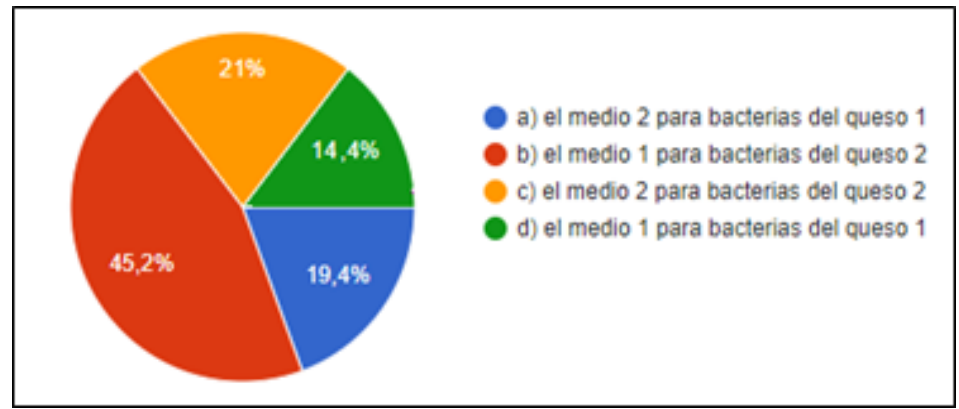

\begin{tabular}{|l|l|}
\hline E.C $8^{\circ}, 9^{\circ}$ & $\begin{array}{l}\text { Registra observaciones y resultados utilizando esquemas, gráficas y tablas. } \\
\text { Establece relaciones entre la información recopilada y los resultados. }\end{array}$ \\
\hline $\begin{array}{l}\text { DBA } \\
7^{\circ}\end{array}$ & $\begin{array}{l}\text { Interpreta los datos representados en diferentes tablas y gráficos. } \\
\text { Plantea preguntas, diseña y realiza un plan para recolectar la información } \\
\text { pertinente. }\end{array}$ \\
\hline
\end{tabular}


Se observa cómo el 45,2\% de los estudiantes respondieron correctamente, pero hay un 54.8\% que no. Esta pregunta pertenece a las pruebas Saber 11 y muestra la necesidad de leer, comprender y obtener información de las tablas de datos, además de plantear y elaborar otras.

Se observa la debilidad al momento de utilizar operaciones básicas que se encuentran en la misma tabla cómo, por ejemplo, sumas y restas, y no de realizarlas sino también de encontrarlas, lo que demuestra la dificultad para entender los planteamientos.

Se demuestra la necesidad de currículos pertinentes, es decir, no fragmentados sino holísticos, que respondan a la complejidad de los sujetos y del contexto.

Al no quedarse solo mirando la habilidad y la competencia, se puede encontrar como enfrentando los problemas desde la transdisciplinariedad se construyen diferentes caminos para solucionar problemas y al encontrar estas formas y métodos se puede trasladar a la sociedad, es decir, una educación que transforme no solo al sujeto sino también al entorno.

E.C: Estándares básicos de competencias.

DBA: Derechos básicos de competencias

5. El cultivo de bacterias lácticas debe satisfacer los criterios de una buena productividad (sostenimiento y desarrollo máximo de bacterias deseadas) y alta selectividad (capacidad para inhibir organismos extraños). De la comparación de los medios frente a estos dos aspectos puede decirse que:

a) el medio 2 es más productivo que el medio 1

b) el medio 1 es más selectivo que el medio 2

c) el medio 1 es más productivo, pero el medio 2 es más selectivo

d) el medio 1 es más selectivo, pero el medio 2 es más productivo

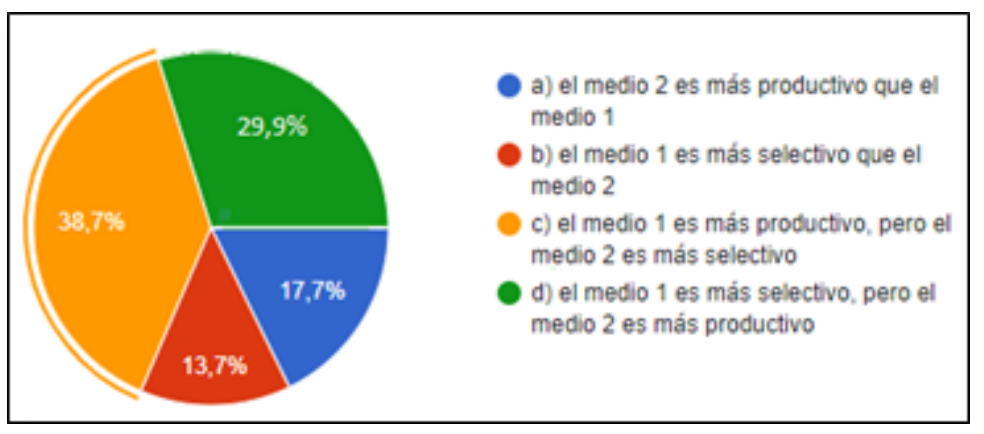

(Examen de Estado. Banco de preguntas de biología)

\begin{tabular}{|l|l|}
\hline E.C $8^{\circ}, 9^{\circ}$ & Establece relaciones entre la información recopilada y saca conclusiones \\
\hline $\begin{array}{l}\text { DBA } \\
7^{\circ}\end{array}$ & Interpreta los datos representados en diferentes tablas y gráficos \\
\hline
\end{tabular}


Se observa cómo el 38,7\% de los estudiantes respondieron correctamente, pero hay un $61,3 \%$ que no. Esta pregunta pertenece a las pruebas Saber 11 y muestra la necesidad de comprender conceptos como bacterias, productividad, selectividad, para entender el problema y así poder analizar la gráfica.

Se siguen presentando deficiencias de lectura de textos y gráficas, por lo que esta es una oportunidad para construir procesos que alcancen mejores niveles de comprensión, pensamiento crítico y divergente, modelizar y plantear nuevas problemáticas, es decir, para razonar a nivel mental y argumentar a nivel social.

Se puede avanzar de la habilidad y la competencia, a construir oportunidades de pensamiento que indaguen y busquen la forma de comprender los fenómenos, es decir, un pensamiento complejo mediado por la comunicación.

E.C: Estándares básicos de competencias.

DBA: Derechos básicos de competencias

\section{ANÁLISIS (CUESTIONARIO DOS)}

La encuesta de actitudes realizada por las estudiantes arrojo información pertinente que permite ser relacionada con los aspectos académicos y que en medio del confinamiento por la pandemia de la COVID-19, permite dar luces acerca de la importancia de avanzar de los modelos por competencias hacia el desarrollo del pensamiento configuracional y crítico.

Tabla 2

Porcentajes de los ítems

\begin{tabular}{|l|c|c|c|c|c|}
\hline & \multicolumn{5}{|c|}{ Porcentaje } \\
\hline & 1 & 2 & 3 & 4 & 5 \\
\hline $\begin{array}{l}\text { 1. Creo que acudiendo a las clases virtuales se opti- } \\
\text { miza el tiempo de estudio. }\end{array}$ & 8.6 & 13.7 & 26.6 & 36 & 15.1 \\
\hline $\begin{array}{l}\text { 2. El trato con los profesores en las clases virtuales } \\
\text { me produce vergüenza/nerviosismo }\end{array}$ & 23.7 & 23 & 23 & 21.6 & 8.6 \\
\hline $\begin{array}{l}\text { 3. Me interesa las clases virtuales porque se adquie- } \\
\text { re soltura en el trato personal }\end{array}$ & 7.2 & 16.5 & 27.3 & 35.3 & 13.7 \\
\hline $\begin{array}{l}\text { 4. No quiero molestar a los profesores asistiendo a } \\
\text { las clases virtuales }\end{array}$ & 52.5 & 24.5 & 14.4 & 6.5 & 2.2 \\
\hline $\begin{array}{l}\text { 5. Las clases virtuales son un medio eficaz para re- } \\
\text { solver dudas }\end{array}$ & 10.1 & 14.4 & 14.4 & 30.2 & 30.9 \\
\hline $\begin{array}{l}\text { 6. No me gustan las clases virtuales porque no se } \\
\text { expresarme bien }\end{array}$ & 23 & 22.3 & 23.7 & 20.1 & 10.8 \\
\hline $\begin{array}{l}\text { 7. Me interesan las clases virtuales porque se apren- } \\
\text { den más conceptos que en el aula }\end{array}$ & 40.3 & 20.1 & 18.7 & 13.7 & 7.2 \\
\hline
\end{tabular}




\begin{tabular}{|l|c|c|c|c|c|}
\hline $\begin{array}{l}\text { 8. Acudiendo a clases virtuales puedes ahorrarte } \\
\text { contratar un profesor particular }\end{array}$ & 20.9 & 14.4 & 20.1 & 25.9 & 18.7 \\
\hline $\begin{array}{l}\text { 9. En clases virtuales me siento incapaz de pensar } \\
\text { con claridad }\end{array}$ & 21.6 & 26.6 & 18.7 & 24.5 & 7.9 \\
\hline $\begin{array}{l}\text { 10. Las clases virtuales son estimulantes para afron- } \\
\text { tar los estudios }\end{array}$ & 9.4 & 12.2 & 30.9 & 29.5 & 18 \\
\hline $\begin{array}{l}\text { 11. Las clases virtuales se centran en lo realmente } \\
\text { importante de las asignaturas }\end{array}$ & 10.1 & 10.1 & 25.2 & 33.8 & 20.9 \\
\hline $\begin{array}{l}\text { 12. No me gustan las clases virtuales porque mues- } \\
\text { tro a mis profesores mis carencias }\end{array}$ & 25.9 & 25.2 & 32.4 & 10.1 & 6.5 \\
\hline $\begin{array}{l}\text { 13. Las clases virtuales pueden mejorar mis hábitos/ } \\
\text { métodos de estudio }\end{array}$ & 11.5 & 23.7 & 15.1 & 30.2 & 19.4 \\
\hline $\begin{array}{l}\text { 14. Una buena opción para ponerme al día en una } \\
\text { materia es acudir a las clases virtuales }\end{array}$ & 7.2 & 10.1 & 15.1 & 36.7 & 30.9 \\
\hline $\begin{array}{l}\text { 15. En clases virtuales no me veo capaz de seguir las } \\
\text { explicaciones de los profesores }\end{array}$ & 13.7 & 26.6 & 26.6 & 19.4 & 13.7 \\
\hline $\begin{array}{l}\text { 16. El trato personal con los profesores puede favo- } \\
\text { recer a la hora de aprobar }\end{array}$ & 18 & 16.5 & 27.3 & 23.7 & 14.4 \\
\hline 17. Prefiero ir en grupo a tutorías virtuales & 10.8 & 16.5 & 24.5 & 18.7 & 29.5 \\
\hline $\begin{array}{l}\text { 18. Entablar confianza con el profesor puede servir- } \\
\text { me de contacto en el futuro }\end{array}$ & 13.7 & 11.5 & 23 & 30.9 & 20.9 \\
\hline
\end{tabular}

Tabla 3

\section{Estadísticas de los ítems}

\begin{tabular}{|c|c|c|c|}
\hline \multicolumn{4}{|c|}{ Estadísticas de elemento } \\
\hline & Media & Desviación & $\mathrm{N}$ \\
\hline $\begin{array}{l}\text { 1. Creo que acudiendo a las clases virtuales se optimiza } \\
\text { el tiempo de estudio. }\end{array}$ & 3,3696 & 1,14034 & 138 \\
\hline $\begin{array}{l}\text { 2. El trato con los profesores en las clases virtuales me } \\
\text { produce vergüenza/nerviosismo }\end{array}$ & 2,6812 & 1,28997 & 138 \\
\hline $\begin{array}{l}\text { 3. Me interesa las clases virtuales porque se adquiere sol- } \\
\text { tura en el trato personal }\end{array}$ & 3,3188 & 1,12688 & 138 \\
\hline $\begin{array}{l}\text { 4. No quiero molestar a los profesores asistiendo a las } \\
\text { clases virtuales }\end{array}$ & 1,8188 & 1,04801 & 138 \\
\hline $\begin{array}{l}\text { 5. Las clases virtuales son un medio eficaz para resolver } \\
\text { dudas }\end{array}$ & 3,5942 & 1,31603 & 138 \\
\hline $\begin{array}{l}\text { 6. No me gustan las clases virtuales porque no se expre- } \\
\text { sarme bien }\end{array}$ & 2,7174 & 1,30126 & 138 \\
\hline $\begin{array}{l}\text { 7. Me interesan las clases virtuales porque se aprenden } \\
\text { más conceptos que en el aula }\end{array}$ & 2,2826 & 1,31243 & 138 \\
\hline
\end{tabular}




\begin{tabular}{|l|c|c|c|}
\hline $\begin{array}{l}\text { 8. Acudiendo a clases virtuales puedes ahorrarte contra- } \\
\text { tar un profesor particular }\end{array}$ & 3,0870 & 1,40634 & 138 \\
\hline $\begin{array}{l}\text { 9. En clases virtuales me siento incapaz de pensar con } \\
\text { claridad }\end{array}$ & 2,7029 & 1,27531 & 138 \\
\hline $\begin{array}{l}\text { 10. Las clases virtuales son estimulantes para afrontar } \\
\text { los estudios }\end{array}$ & 3,3623 & 1,17107 & 138 \\
\hline $\begin{array}{l}\text { 11. Las clases virtuales se centran en lo realmente im- } \\
\text { portante de las asignaturas }\end{array}$ & 3,4710 & 1,20335 & 138 \\
\hline $\begin{array}{l}\text { 12. No me gustan las clases virtuales porque muestro a } \\
\text { mis profesores mis carencias }\end{array}$ & 2,4565 & 1,17218 & 138 \\
\hline $\begin{array}{l}\text { 13. Las clases virtuales pueden mejorar mis hábitos/mé- } \\
\text { todos de estudio }\end{array}$ & 3,2391 & 1,31001 & 138 \\
\hline $\begin{array}{l}\text { 14. Una buena opción para ponerme al día en una mate- } \\
\text { ria es acudir a las clases virtuales }\end{array}$ & 3,7609 & 1,18725 & 138 \\
\hline $\begin{array}{l}\text { 15. En clases virtuales no me veo capaz de seguir las ex- } \\
\text { plicaciones de los profesores }\end{array}$ & 2,9203 & 1,25018 & 138 \\
\hline $\begin{array}{l}\text { 16. El trato personal con los profesores puede favorecer } \\
\text { a la hora de aprobar }\end{array}$ & 3,0145 & 1,30124 & 138 \\
\hline 17. Prefiero ir en grupo a tutorías virtuales & 3,4130 & 1,33853 & 138 \\
\hline $\begin{array}{l}\text { 18. Entablar confianza con el profesor puede servirme } \\
\text { de contacto en el futuro }\end{array}$ & 3,3551 & 1,29457 & 138 \\
\hline
\end{tabular}

Se observa como en el ítem 1, "creo que acudiendo a las clases virtuales se optimiza el tiempo de estudio", con una media de 3.4, el 15.1\% de las estudiantes estuvo totalmente de acuerdo, por lo que muestran que necesitan orientación para el manejo del tiempo y la autonomía y que los maestros propongan experiencias que promuevan la lectura, la solución de problemas, la asociación de áreas, la interpretación, la argumentación, es decir, que inviten al reto y esfuerzo.

Se observa como en el ítem 2, "el trato con los profesores en las clases virtuales me produce vergüenza/nerviosismo", con una media de 2.7 , el 8.6\%, estuvo totalmente de acuerdo, lo que muestra que si bien, es bajo, es necesario que desde las instituciones educativas, se realice un trabajo conjunto entre directivas, psicoorientación, padres de familia, estudiantes y profesores, para que se construyan más ambientes de comunicación, participación y empatía, lo cual repercute en los resultados académicos.

Se observa como en el ítem 3, "me interesa las clases virtuales porque se adquiere soltura en el trato personal", con una media de 3.3, el 13.7\%, estuvo totalmente de acuerdo, lo cual se relaciona con el ítem anterior, demostrando que es necesario ofrecerles a las estudiantes espacios para que se puedan comunicar, expresen lo que sienten y establezcan relaciones interpersonales 
mediante el trabajo en equipo y la colaboración.

Se observa como en el ítem 4, "no quiero molestar a los profesores asistiendo a las clases virtuales", con una media de 1.8, el 52.5\%, estuvo en desacuerdo, demostrando ganas e interés en cumplir sus responsabilidades y aunque los porcentajes, "de acuerdo" y "totalmente de acuerdo", fueron bajos, es necesario pensar en ellos para planear y aplicar clases motivantes y retadoras, que no se queden solo en el desarrollo de la destreza y la habilidad sino que los atraiga al pensamiento crítico, reflexivo y creativo.

Se observa como en el ítem 5, "las clases virtuales son un medio eficaz para resolver dudas", con una media del 3.6, el $30.9 \%$, estuvo totalmente de acuerdo y el $10.1 \%$, estuvo totalmente en desacuerdo, demuestra que la labor educativa en tiempos de contingencia sanitaria, no debe quedarse solo en el acto de utilizar plataformas para el trabajo remoto, sino que se deben convertir en verdaderos espacios de conocimiento y socialización, donde se promueva en el estudiante la oportunidad de comunicación, expresión, reflexión, crítica, creatividad, solución de problemas, etc, es decir, un ambiente que aún en la distancia respete la heterogeneidad de los sujetos en formación.

Se observa como en el ítem 6, "no me gustan las clases virtuales porque no se expresarme bien", con una media de 2.7 , el 10.8\%, estuvo totalmente de acuerdo y los demás ítems estuvieron muy parejos, por ejemplo, el $23 \%$, estuvo totalmente en desacuerdo. Esto indica que es necesario intervención por parte de psicoorientación institucional, para mostrar a las estudiantes lo importante que son las relaciones interpersonales y que aún en tiempos de confinamiento es necesario fortalecer los lazos de comunicación y expresión.

Se observa como en el ítem 7, "me interesan las clases virtuales porque se aprenden más conceptos que en el aula", con una media de 2.3 , solo el $7.2 \%$, estuvo de acuerdo y el $40.3 \%$, estuvo en desacuerdo. Esto muestra el papel fundamental del maestro como referente del estudiante, tanto en lo comportamental como en lo académico. Es una oportunidad para la formación del docente lo cual repercute en las prácticas de aula. El estudiante muestra que necesita una figura que lo guíe en la construcción de su aprendizaje y que debe fortalecer su autonomía.

Se observa como en el ítem 8, "acudiendo a clases virtuales puedes ahorrarte contratar un profesor particular", con una media de 3.1, el 18.7\%, estuvo totalmente de acuerdo y el $20.9 \%$, totalmente en desacuerdo, muy parejos, lo mismos sucedió con los otros ítems. Se puede ver como las clases virtuales, poco a poco llenan las expectativas de las estudiantes y confían en sus docentes, pero relacionándola con el ítem anterior, es necesario mejorar las prácticas educativas, que sean 
relevantes al contexto y permitan la motivación, el pensamiento crítico y reflexivo.

Se observa como en el ítem 9, "en clases virtuales me siento incapaz de pensar con claridad", con una media de 2.7 , solo el $7.9 \%$, estuvo totalmente de acuerdo y el $21.6 \%$, estuvo totalmente en desacuerdo, indicando que en la medida que se implementan clases virtuales motivantes, reflexivas, que promuevan el diálogo, el respeto y la argumentación, los estudiantes encontraran la oportunidad de construir pensamiento crítico y transformador de su propio entorno.

Se observa como en el ítem 10, "las clases virtuales son estimulantes para afrontar los estudios", con una media de 3.4, el 18\%, estuvo totalmente de acuerdo y el 9.4\%, estuvo totalmente en desacuerdo. Estos resultados muestran relación con los ítems anteriores, donde se ve la necesidad de construir clases retadoras, que muevan el aprendizaje, de estados pasivos hacia verdaderos procesos de pensamiento configuracional y crítico, mediante el reto, el problema, la pregunta, donde el estudiante descubra que lo que aprende, lo puede aplicar a su propio contexto, que es lo que se busca, transformar la sociedad.

Se observa como en el ítem 11, "las clases virtuales se centran en lo realmente importante de las asignaturas", con una media de 3.5, el 20.9\%, estuvo totalmente de acuerdo y el 10.1\%, totalmente en desacuerdo, lo cual, relacionándolo con los ítems anteriores, demuestra la necesidad de construir currículos pertinentes y activos para su propia cotidianidad, donde el estudiante encuentre la oportunidad de poder expresarse con sentido crítico, para trasladarse de lo individual a lo grupal y social.

Se observa como en el ítem 12, "no me gustan las clases virtuales porque muestro a mis profesores mis carencias", con una media de 2.5 , solo el $6.5 \%$, estuvo totalmente de acuerdo y el 25.9\%, totalmente en desacuerdo. Esto demuestra, que es necesario fomentar en las clases, la oportunidad del diálogo, la comunicación y la afectividad, la oportunidad para que las estudiantes se abran al cambio y aprovechen sus experiencias, las cuales son de gran valor, y así los estudiantes construyan autonomía y autoconfianza.

Se observa como en el ítem 13, "las clases virtuales pueden mejorar mis hábitos/métodos de estudio", con una media de 3.2, el 19.4\%, estuvo totalmente de acuerdo y el $11.5 \%$, estuvo totalmente en desacuerdo, indicando así, que, en medio de la contingencia, las instituciones deben implementar estrategias para el autoaprendizaje, la autonomía y la disciplina en medio de la heterogeneidad, como formas de alcanzar mejores niveles de desarrollo y encuentre sentido y significado a lo que aprende en el contexto, el cual es problémico y cambiante. 
Se observa como en el ítem 14, "una buena opción para ponerme al día en una materia es acudir a las clases virtuales", con una media de 3.8, el 30.9\%, estuvo totalmente de acuerdo y el 7.2\%, totalmente en desacuerdo, muestra como los estudiantes ven en las clases virtuales una oportunidad para continuar con su proceso de formación, pero de todas maneras, es necesario realizar un trabajo para transformar las prácticas educativas en verdaderos espacios de pensamiento crítico, deliberación, argumentación, interpretación, representación e intencionalidad del propio contexto.

Se observa como en el ítem 15, “en clases virtuales no me veo capaz de seguir las explicaciones de los profesores", con una media de 2.9 , las estudiantes que estuvieron totalmente de acuerdo y las que estuvieron totalmente en desacuerdo, coincidió en un $13.7 \%$, por lo que es necesario que las clases virtuales pasen de ser de carácter unidireccional, a un estado de diálogo y deliberación, donde el aprendizaje se construya de forma colaborativa, dinámica y abierta y haya oportunidad para la expresión de creencias, sentimientos y emociones.

Se observa como en el ítem 16, "el trato personal con los profesores puede favorecer a la hora de aprobar", con una media de 3.0, el 14.4\%, estuvo totalmente de acuerdo y el 18\%, estuvo totalmente en desacuerdo, indica que es necesario trabajar en las estudiantes acerca de la importancia y el autoconvencimiento del esfuerzo, la dedicación para alcanzar metas y propósitos, que el proceso educativo y formativo no es de amiguismos, es de confianza, de respeto en medio de la diversidad, con convencimiento de las capacidades y potencialidades propias.

Se observa como en el ítem 17, "prefiero ir en grupo a tutorías virtuales”, con una media de 3.4 , el $29.5 \%$, estuvo totalmente de acuerdo y el $10.8 \%$, totalmente en desacuerdo, muestra como a las estudiantes les gusta el trabajo en equipo y que es necesario aprovechar esta oportunidad para fortalecerlo, para superar el individualismo, lo que posibilita la participación para alcanzar niveles de pensamiento profundo, crítico y reflexivo, cargado de intención, responsabilidad, sentidos y significados, además que las prácticas educativas deben procurar por construir situaciones que produzcan emociones positivas, que valoren no solo los aspectos intelectuales, sino también los afectivos.

Se observa como en el ítem 18, “entablar confianza con el profesor puede servirme de contacto en el futuro", con una media de 3.4, el 20.9\%, estuvo totalmente de acuerdo y el 13.7\%, totalmente en desacuerdo, lo que indica que el individuo en su transformación a sujeto responsable debe descubrir por si solo y con sus semejantes que hay una completa relación de interdependencia con el capital humano y que lo que aprende en su institución educativa, lo debe aplicar en su entorno, 
como forma de mejorar la sociedad, mediante la implementación de propuestas constructivas, reflexivas y racionales.

\section{DISCUSIÓN}

Al relacionar la información suministrada por los cuestionarios 1 y 2, se observa la necesidad, que no solo en la virtualidad, sino también en la presencialidad, surge de orientar los currículos de los proyectos educativos institucionales (PEI), a pasar del modelo por competencias, al modelo sociocrítico, que propenda por desarrollar el pensamiento configuracional, sino, se seguirá transformando individuos en sujetos, con destrezas encaminadas solo para el mundo laboral, lo cual no se esta afirmando que sea negativo, al contrario, es bueno para el estado económico implantado en el país, pero que deja pasar por alto, las grandes potencialidades de las personas en formación.

Los resultados muestran en las estudiantes las falencias que presentan en manejo de operaciones básicas matemáticas y sin quedarse solo en lo operacional, hay dificultades para descubrirlas en los problemas, lo que indica, deficiencias en el análisis de gráficas, tablas y en la comprensión de lectura de diferentes clases de textos, su interpretación, análisis y argumentación.

Se puede pensar entonces en la responsabilidad del docente en cuanto a su didáctica y al momento de planear las clases, porque si bien, se está atravesando una época difícil debido al confinamiento y alejamiento de las aulas de clase presenciales, las estrategias remotas y virtuales, no pueden ser excusa para continuar con la unidireccionalidad en el proceso educativo, además que se deben tener en cuenta las actitudes y expectativas de los estudiantes.

Que sea esta una oportunidad de mejoramiento de la labor educativa donde se le proponga a los estudiantes verdaderos espacios de construcción del conocimiento, mediante el trabajo colaborativo, diálogo, comprensión, argumentación, interpretación, creación, es decir, un proceso donde los sujetos encuentren el acto educativo como un reto y descubran su papel como agentes transformadores de sociedad y así el sistema cumpla con la función que le fue encomendada.

Así, mediante el reto propuesto por los docentes, el desarrollo del pensamiento configuracional, será también social, debido a que se rediseñará el entorno, al interpretar los procesos sociales como procesos de desarrollo humano y al aplicar los conocimientos en contextos problémicos y cambiantes. 


\section{REFERENCIAS BIBLIOGRÁFICAS}

Alvarez, I y Fuentes, H. (Sin fecha).La formación por la contemporaneidad. Modelo holísticoconfiguracional de la didáctica de la educación superior. Disponible en: http://cidc.udistrital.edu. co/investigaciones/documentos/revistacientifica/rev5/vol2/1La\%20formacion.pdf

Alvarez, I. Fuentes, H y Matos E (2004). La teoría Holístico-configuracional en los procesos sociales. Revista pedagogía universitaria. 9(1). Disponible en: http://cvi.mes.edu.cu/peduniv/index. php/peduniv/article/view/273/264

Castro, E (2013). Perspectiva pedagógica sociocrítica, otra forma de concebir la escuela en Colombia. Revista Quaestiones Disputatae. (12). 77-94. Disponible en:file:265-Texto\%20del\%20 art\%C3\%ADculo-1601-2-10-20200402\%20(1).pdf

Comboni,SyJuárez,J(2012). Epistemología delpensamientocomplejo. Reencuentro.65.38-51. Disponible en: http://www.redalyc.org/pdf/340/34024824006.pdf

De Alba, N, García, F y Santiesteban, A (2012). Educar para la participación ciudadana en la enseñanza de las ciencias sociales. Volumen II. Disponible en: http:/www.didactica-cienciassociales.org/publicaciones_archivos/2012-sevilla-XXIII-Simposio-DCS_I.pdf

Derechos Básicos de Aprendizaje. DBA. (2016) Matemáticas. MINEDUCACIÓN.V.2. Disponible en: file:DBA_Matem\%C3\%A1ticas.pdf

Examen de Estado. Banco de preguntas de biología. 59-60. Disponible en: file://C:/Users/ ASUS/Downloads/Biologia_Banco_de_preguntas_ICFES.pdf

Gómez, J y Gómez, L (2011). Elementos teóricos y prácticos de la pedagogía crítica: más allá de la educación, metáfora, escena y experiencia. Praxis. Disponible en: DialnetElementosTeoricosYPracticosDeLaPedagogiaCriticaMas-4638339\%20(1).pdf

Minte, A e Ibagón, N (2017). Pensamiento crítico: ¿competencia olvidada en la enseñanza de la historia? Entramado. 13 (2). 186-198. Disponible en: http://www.scielo.org.co/pdf/entra/ v13n2/1900-3803-entra-13-02-00186.pdf

Mora, D (2014). Modelo crítico para la evaluación y seguimientode la calidad educativa, 
desempeño escolar y factores asociados. Integra Educativa. VII. (2). 13-32. Disponible en: http:// www.scielo.org.bo/pdf/rieiii/v7n2/v7n2_a02.pdf

Ortiz, A (2011). Hacia una nueva clasificación de los modelos pedagógicos: el pensamiento configuracional como paradigma científico y educativo del siglo XXI. Revista Praxis. (7). 121-137. Recuperado de: file: Dialnet-HaciaUnaNuevaClasificacionDeLosModelosPedagogicos-5907183. pdf

Ortiz, A (2014). ¿Cómo se entrenan y se modifican la mente y el cerebro humano? Revista de Psicología GEPU.5. (2). 147-164. Disponible en: Como_se_entrenan_y_se_modifican_el_cereb. pdf

Ortiz, A (2017). Configuración epistémica de la pedagogía. Tendencias que han proliferado en la historia de la educación. Rev.hist.educ.latinoam. 19(29). 165-195. Disponible en: http://www. scielo.org.co/pdf/rhel/v19n29/0122-7238-rhel-19-29-00165.pdf

Oviedo y Campo-Arias (2005). Metodología de investigación y lectura crítica de estudios. Aproximación al uso del coeficiente de Cronbach. Revista Colombiana de Psiquiatría. XXXIV (4). 572-580. Disponible en: cronbach\%202.pdf

Rodríguez,J(2014). Aproximación a un modelo teórico de participación social que fortalezca la calidad de vida desde el contexto de la educación venezolana. Tesis doctoral. Universidad de Córdoba. Disponible en: https://helvia.uco.es/xmlui/bitstream/handle/10396/12022/2014000000897. pdf? sequence $=1$ \&isAllowed $=\mathrm{y}$

Salcedo, M y Ortiz, A (2017). Análisis epistémico del pensamiento configuracional. Revista Zona Próxima. (26). Disponible en: http://rcientificas.uninorte.edu.co/index.php/zona/article/ view/6652/10180

Sánchez, L y Viveros, S (2018). La gestión académica del modelo pedagógico sociocrítico en la institución educativa: rol del docente. Universidad y sociedad. 10 (5). 424-433. Disponible en: http://scielo.sld.cu/pdf/rus/v10n5/2218-3620-rus-10-05-424.pdf

Serie Guía N7. Formar en ciencias: ¡el desafío!. (2004). Estándares Básicos de Competencias en Ciencias Naturales y Ciencias Sociales. Ministerio de educación Nacional. Disponible en: https://www.mineducacion.gov.co/1759/articles-81033_archivo_pdf.pdf 
Unzueta, S (2011). Algunos aportes de la psicología y el paradigma sociocrítico a una educación comunitaria crítica y reflexiva. Integra educativa. IV. (2). 105-144. Disponible en: http:// www.scielo.org.bo/pdf/rieiii/v4n2/v4n2a06.pdf 